\title{
Investigation into the effect of silica nanoparticles on the rheological characteristics of water-in-heavy oil emulsions
}

\author{
O. S. Alade ${ }^{1}$ D. A. Al Shehri ${ }^{1}$ M. Mahmoud ${ }^{1}$
}

Received: 22 November 2018 / Published online: 4 June 2019

(c) The Author(s) 2019

\begin{abstract}
The effect of silica nanoparticles on the rheological characteristics of water-in-heavy oil emulsions has been investigated. Enhanced oil recovery methods for heavy oil production (most especially, thermal fluid injection) usually result in the formation of water-in-oil (W/O) emulsion. In reality, the emulsion produced also contains some fine solid mineral particles such as silica, which, depending on its quantity, may alter the viscosity and/or rheological properties of the fluid. A series of binary-component emulsions were separately prepared by dispersing silica nanoparticles [phase fraction, $\beta_{\mathrm{s}},=0.5 \%-5.75 \%$ $(\mathrm{wt} / \mathrm{v})$ ] in heavy oil (S/O suspension) and by dispersing water [water cut, $\theta_{\mathrm{w}}=10 \%-53 \%(\mathrm{v} / \mathrm{v})$ ] in heavy oil (W/O emulsion). Ternary-component emulsions comprising heavy oil, water droplets and suspended silica nanoparticles (S/W/O) were also prepared with similar ranges of $\theta_{\mathrm{w}}$ and $\beta_{\mathrm{s}}$. The viscosity was measured at different shear rates $\left(5.1-1021.4 \mathrm{~s}^{-1}\right)$ and temperatures $\left(30-70{ }^{\circ} \mathrm{C}\right)$. Both binary-component and ternary-component emulsion systems were observed to exhibit nonNewtonian shear thinning behaviour. The viscosity of the heavy oil and W/O emulsions increased in the presence of silica nanoparticles. The effect was, however, less significant below $\beta_{\mathrm{s}}=2 \%(\mathrm{wt} / \mathrm{v})$. Moreover, a generalized correlation has been proposed to predict the viscosity of both binary-component and ternary-component emulsions.
\end{abstract}

Keywords Heavy oil emulsions $\cdot$ Heavy oil-silica nanoparticle suspension $\cdot$ Viscosity functions $\cdot$ Rheological model . Complex fluid

\section{Introduction}

An emulsion is basically a binary-component liquid-liquid system in which droplets of one liquid are dispersed in the other (Fakoya and Ahmed 2018). It is referred to as a colloidal suspension when solid particles are dispersed in the liquid phase. Emulsions are frequently encountered during petroleum recovery, production, separation and transportation operations (Martinez-Palou et al. 2015; Wong et al. 2015; Wen et al. 2016; Zadymova et al. 2017; Perazzo et al. 2018). The phenomenon has therefore received significant

Edited by Yan-Hua Sun

O. S. Alade

olalekan.alade@kfupm.edu.sa

D. A. Al Shehri

alshehrida@kfupm.edu.sa

1 Department of Petroleum Engineering, College of Petroleum and Geosciences, King Fahd University of Minerals and Petroleum, Dhahran, Saudi Arabia attention due to its technical and economic importance (Wong et al. 2015; Alade et al. 2016a, b, c; Zadymova et al. 2017; Perazzo et al. 2018).

Essentially, within the reservoir or at the surface, the formation of emulsions is triggered by an energy input, which is traditionally supplied through shaking, stirring or some other kinds of intensive dynamic and/or static mixing forces. The process is usually aided by the presence of surface-active substances (such as synthetic chemical surfactant, natural hydrocarbon surfactant: asphaltene and resins and solid mineral particles) that contribute to stabilizing the particles of the dispersed phase (Clausse et al. 2005; Martinez-Palou et al. 2011, 2015; Wong et al. 2015; Wen et al. 2016; Alade et al. 2016a, b; Kumar and Mahto 2017).

The popularly reported types of emulsions encountered in the petroleum industry include the binary-component waterin-oil (W/O) and oil-in-water (O/W) emulsions (MartinezPalou et al. 2011; Pal 2011; Balsamo et al. 2014; Sefton and Sinton 2010; Mandal and Bera 2015; Alade et al. 2016a; Zadymova et al. 2017; Kumar and Mahto 2017). Several studies have been carried out on these types of emulsions. 
Some of these include the study of formation and separation mechanisms (Kuo and Lee 2010; Fortuny et al. 2007; Fingas and Fieldhouse 2014; Martinez-Palou et al. 2015), interfacial behaviour (Sjoblom et al. 2003; Yarranton et al. 2007; Dehghan et al. 2015; Schulz et al. 2016) and pipeline transportation (Langevin et al. 2004; Salager et al. 2001; Martinez-Palou et al. 2011; Al-Yaari et al. 2014; Malkin et al. 2017; Kumar and Mahto 2017).

Certain operations, most especially thermal fluid injections during the enhanced recovery of heavy oil, commonly result in the formation of a W/O emulsion which exhibits higher viscosity than the original oil (Sefton and Sinton 2010; Mandal and Bera 2015). Furthermore, in a loose sandstone heavy oil reservoir, as a result of the higher density and viscosity of heavy oil (Xie et al. 2014), sand particles may be released by colloidal forces or mobilized by hydrodynamic shear of the fluid flowing through porous media. Similarly, during secondary and enhanced oil recovery operations including water flooding, injection of chemicals or surfactant slug and nanofluid injection, complex emulsions may be formed, comprising more than two components, in the wellbore and the production line. Such occasions, as reported by Jamaluddin and Bowen (1994), may occur during the downhole emulsification for heavy oil production by alkaline/surfactant flooding. Therefore, it often occurs in reality that the produced W/O emulsion contains solid particles, which may significantly affect the rheological characteristics of the fluid depending on the volume fraction present (Pal et al. 1992; Jamaluddin and Bowen 1994; Maria and Ilyin 2018).

Although there are many studies of the viscosity and/ or rheological characteristics and modelling of the binarycomponent emulsions ( $\mathrm{Pal}$ and Rhodes 1989; Jamaluddin and Bowen 1994; Tadros 1994; Aomari et al. 1998; Pal 2001; Johnson and Ronningsen 2003; Luo and Gu 2007; Sefton and Sinton 2010; Schuch et al. 2013; Pal 2014; Mandal and Bera 2015), similar investigations into rheological characteristics of ternary-component emulsions, comprising heavy oil-water with added solids, have been rarely reported. Nonetheless, the only known viscosity function for the ternary-component emulsion (water-in-oil emulsion with clay particles) was proposed by Pal et al. (1992).

The motivation for the present study is primarily informed by the importance of silica as a component of the reservoir rocks (Liu et al. 2012; Youssif et al. 2018) and the tendency of the heavy oil emulsion to get contaminated with such particles. More so, as stated by Youssif et al. (2018), close to $100 \%$ of silica nanoparticles used in nanofluid-enhanced oil recovery are silicon dioxide, which is the main component of sandstones. Furthermore, depending on the methods of extraction, it has been observed (Maria and Ilyin 2018) that heavy crude oil may contain some quantity of mechanical admixtures of solids such as clay and silica. As earlier stated, these solid particles may either stabilize the emulsion or increase its viscosity (Pal et al. 1992; Maria and Ilyin 2018).

Therefore, in this work, a series of binary-component and ternary-component emulsions were studied to quantify the effect of silica nanoparticles on the viscosity. Ultimately, an empirical model was proposed to predict the rheological characteristics of both binary- and ternary-component emulsion systems under specified conditions.

\section{Brief review of viscosity models for two-component emulsion systems}

For reference purposes, a brief review of some of the earlier work on two-component emulsion viscosity functions is provided. The viscosity of a two-component suspension has been modelled by considering the fluid as a hypothetical one-phase (pseudo-homogeneous) system (Bird et al. 2007). As expressed in Eq. 1, the viscosity of this type of system is usually expressed as a function of the volume/weight fraction of the dispersed phase (Soleymanzadeh et al. 2018):

$\mu_{\text {eff }}=\mu(\theta)$

where $\mu_{\text {eff }}$ is the effective viscosity of the pseudo-homogeneous fluid (emulsion), $\mathrm{cP}$, and $\theta$ is the weight fraction of the dispersed phase (water or solids). The ratio of the effective viscosity of the emulsion to the viscosity of the continuous phase is the relative viscosity $(\eta)$-Eq. 2 :

$\eta=\frac{\mu_{\text {eff }}}{\mu_{\mathrm{o}}}$

In pioneering this concept, Einstein (1956) developed an empirical model (Eq. 3) for an infinitely dilute suspension of spheres, whereby the particle-particle interaction is assumed negligible. In other words, the movement of one sphere within the fluid does not influence the fluid flow in the neighbourhood of any other spheres. Given a colloidal suspension with the viscosity of the continuous phase $\mu_{\mathrm{o}}$, the Einstein function is expressed as:

$\frac{\mu_{\text {eff }}}{\mu_{\mathrm{o}}}=1+\frac{5}{2} \theta$

The Einstein equation is valid at very low $\theta(<0.1)$. The modifications that followed this function considered an analogue derivation by replacing the shape constant $(2 / 5)$ in the Einstein equation with different coefficients for dilute suspensions of particles of various shapes. Such functions include the Sherman polynomial equation-Eq. 4 (Sherman 1968), for emulsions with finite concentration:

$\frac{\mu_{\mathrm{eff}}}{\mu_{\mathrm{o}}}=1+a \theta+b \theta^{2}+c \theta^{3}+\cdots$

where $a, b$ and $c$ are the empirical parameters. 
Table 1 Physical properties of crude oil

\begin{tabular}{lllllllll}
\hline Oil gravity, ${ }^{\circ} \mathrm{API}$ & IFT, $\mathrm{mN} / \mathrm{m}$ & \multicolumn{7}{l}{ Density at different temperatures $\rho, \mathrm{g} / \mathrm{cm}^{3}$} \\
\cline { 2 - 8 } & & $25^{\circ} \mathrm{C}$ & $35^{\circ} \mathrm{C}$ & $45{ }^{\circ} \mathrm{C}$ & $55^{\circ} \mathrm{C}$ & $65^{\circ} \mathrm{C}$ & $75^{\circ} \mathrm{C}$ & $85^{\circ} \mathrm{C}$ \\
\hline 20 & 11.12 & 0.9253 & 0.9165 & 0.908 & 0.8979 & 0.8865 & 0.8745 & 0.864 \\
\hline
\end{tabular}

Another function developed by Taylor (1932) for dilute emulsions or suspensions of tiny droplets assumed that the suspended materials undergo an internal circulation without deforming their spherical shape. The Taylor function for twocomponent suspensions with the viscosity of the dispersed phase $\mu_{i}$ and that of the continuous phase $\mu_{\mathrm{o}}$ is given in Eq. 5:

$\frac{\mu_{\mathrm{eff}}}{\mu_{\mathrm{o}}}=1+\left(\frac{\mu_{\mathrm{o}}+5 / 2 \mu_{i}}{\mu_{\mathrm{o}}+\mu_{i}}\right) \theta$

For concentrated suspensions $(\theta>5 \%)$, a complex fluid tends to exhibit non-Newtonian characteristics. Thus, functions such as the Mooney semiempirical equation-Eq. 6 (Mooney 1952), have been used to predict the viscosity:

$\frac{\mu_{\mathrm{eff}}}{\mu_{\mathrm{o}}}=\exp \left(\frac{5 / 2 \theta}{1-\theta / c}\right)$

The empirical constant $c$ has been reported between 0.52 and 0.74 .

Equation 7 is the Eilers function which was developed by Eilers (1941) to fit the viscosity of bitumen emulsions.

$\frac{\mu_{\text {eff }}}{\mu_{\mathrm{o}}}=\left(1+\frac{1.25 \theta}{1-c \theta}\right)^{2}$

Another equation for the viscosity of concentrated binarycomponent systems is the modification proposed by $\mathrm{Pal}$ (1998). This function (Eq. 8) is a form of generalized Roscoe function-Eq. 9 (Roscoe 1952).

$\frac{\mu_{\mathrm{eff}}}{\mu_{\mathrm{o}}}=(1-c \theta)^{-v}$

$\frac{\mu_{\text {eff }}}{\mu_{\mathrm{o}}}=(1-\theta)^{-2.5}$

where $v$ is an empirical parameter.

Detailed discussion about other functions for two-component dispersion systems is available elsewhere in the literature (Bird et al. 2007; Soleymanzadeh et al. 2018). Specifically, for heavy oil emulsions, Eqs. 6, 7 and 9 have been employed by Luo and Gu (2007) and Sefton and Sinton (2010), to fit the viscosity data for heavy oil-asphaltene suspensions and water-in-heavy oil emulsions, respectively. In this work, another viscosity function which is a form of the Arrhenius equation (Eq. 10) is considered to describe the viscosity of two-component heavy oil emulsions/suspensions.

$\frac{\mu_{\text {eff }}}{\mu_{\mathrm{o}}}=\alpha \exp (\beta \theta)$ where $\alpha$ and $\beta$ are the empirical parameters.

The modified form of Eq. 6 which was proposed by Pal et al. (1992) to predict the viscosity of a complex ternarycomponent water-in-oil emulsion with added clay particles is given as follows (Eq. 11):

$\left(\frac{\mu_{\text {swo }}}{\mu_{\text {so }}}\right)_{\dot{\gamma}}=\exp \left(\frac{5 / 2 \theta}{1-\theta / c}\right)$

where the fraction of the dispersed water $(\theta)$ ranges from $0 \%$ to $60 \% ; \mu_{\text {swo }}$ and $\mu_{\text {so }}$ are the viscosities of the ternarycomponent and binary-component systems, respectively, $\mathrm{cP}$; and $\dot{\gamma}$ is the shear rate, $\mathrm{s}^{-1}$.

However, this function requires that the viscosity of the binary-component system is known in order to predict the ternary-component system. Moreover, the ranges of shear rates and the temperature were not clear.

\section{Materials and methodology}

\subsection{Materials}

The physical properties of a heavy oil sample used are given in Table 1. Silicon dioxide $\left(\mathrm{SiO}_{2}\right)$ nanopowder $(10-20 \mathrm{~nm}$ particle size), with molecular weight of $60.08 \mathrm{~g} / \mathrm{mol}$ and density of $2.2-2.6 \mathrm{~g} / \mathrm{mol}$ at $25^{\circ} \mathrm{C}$, was supplied by Aldrich and used without wettability modification. Distilled water was used as the aqueous phase.

\subsection{Methodology}

\subsubsection{Preparation of heavy oil emulsion/suspension mixtures}

A series of binary-component systems (i) heavy oil-silica nanoparticle suspensions- $\mathrm{S} / \mathrm{O}$ and (ii) water-in-heavy oil emulsions (W/O) and ternary-component systems (admixture of heavy oil, silica and water-S/W/O) were prepared for this study. Heavy oil-silica suspensions were prepared by mixing silica powder with the crude oil at weight fractions $\left(\beta_{\mathrm{s}}\right)$ of $0.5 \%-5.75 \%(\mathrm{wt} / \mathrm{v})$. Water-in-oil emulsions with $10 \%-53 \%$ $(\mathrm{v} / \mathrm{v})$ water cut $\left(\theta_{\mathrm{w}}\right)$ were prepared by mixing water with heavy oil without adding a chemical surfactant. The ternary-component systems comprising the heavy oil-silica suspensions (weight fraction $0.5 \%-5.5 \%(\mathrm{wt} / \mathrm{v})$ ) with added water fractions $(10 \%-53 \%(\mathrm{v} / \mathrm{v}))$ were also prepared by mixing water with the oil-silica-based system also without a surfactant. 


\subsubsection{Viscosity tests}

Viscosity of the systems was measured using an Ofite viscometer (Model 900, OFI Testing Equipment Inc., Houston Texas, USA) which is a type of Couette coaxial cylindrical and rotational viscometer. The instrument was regularly calibrated before each test and was interfaced with a computer for data collection. About $160 \mathrm{~mL}$ of dispersion sample was used for each test run. The viscometer was set to precondition the sample by homogenizing it at a speed of $300 \mathrm{rpm}$ and $30^{\circ} \mathrm{C}$ for $5 \mathrm{~min}$. The viscometer was operated at low shear rate of $5.1 \mathrm{~s}^{-1}$ to high shear rate of $1021.4 \mathrm{~s}^{-1}$ at $30-70{ }^{\circ} \mathrm{C}$ and was also set to repeat the test from high to low shear rate, accordingly.

\subsubsection{Viscosity and bulk rheological modelling}

In order to provide a basis for the bulk rheological model for ternary-component systems, experimental data obtained from the binary-component systems (heavy oil-silica nanoparticle suspension and water-in-heavy oil emulsion) were first fitted to the selected equations from the viscosity functions earlier discussed (Eqs. 6, 7, 8 and 10), at different temperatures and shear rates. Subsequently, the Arrhenius function (Eq. 10) was expanded (to accommodate temperature) and was combined with the power law function to model the rheology of the three-component systems.

Generally, for fluid rheology, the power law for the nonNewtonian fluids (de Waele 1923; Ostwald 1925) is expressed as given in Eq. 12.

$\mu_{\mathrm{a}}=K\left(\frac{\mathrm{d} v_{x}}{\mathrm{~d} y}\right)^{n-1}$

where $K$ is the flow consistency index, $\mathrm{mPa} \mathrm{s} ; n$ is the flow behaviour index; $\frac{\mathrm{d} v_{x}}{\mathrm{~d} y}$ is velocity gradient, $\mathrm{s}^{-1}$; and $\mu_{\mathrm{a}}$ is the apparent viscosity, $\mathrm{mPa}$ s.

$K$ can be expressed in the form of the Arrhenius function (Eq. 10). Then, the calculated $K$ from Eq. 12 was fitted to the function presented in Eq. 13.

$K=k_{0} \exp \left(\varphi \beta_{\mathrm{s}}+\omega \theta_{\mathrm{w}}+\frac{\phi}{T_{\mathrm{e}}}\right)$

where $k_{0}$ is the pre-exponential factor of flow consistency index, $\mathrm{mPa} \mathrm{s}{ }^{n} ; \varphi, \omega$ and $\phi$ are the empirical coefficients; $T_{\mathrm{e}}$ is the shearing temperature of emulsion, ${ }^{\circ} \mathrm{C} ; \beta_{\mathrm{s}}$ is the weight fraction of silica nanoparticles, $\%(\mathrm{wt} / \mathrm{v})$; and $\theta_{\mathrm{w}}$ is water fractions, \% (v/v).

Equations 12 and 13 are then combined to predict the viscosity of the binary-component and the ternary-component systems (Eq. 14). $\mu_{\mathrm{ws}}=k_{0} \exp \left(\varphi \beta_{\mathrm{s}}+\omega \theta_{\mathrm{w}}+\frac{\phi}{T_{\mathrm{e}}}\right)\left(\frac{\mathrm{d} v_{x}}{\mathrm{~d} y}\right)^{n-1}$

\subsubsection{Statistical error analysis}

The accuracy of the viscosity function was evaluated by examining the following statistical parameters:

$\mathrm{ARE} \%=\frac{100}{N_{\mathrm{d}}} \sum_{i=1}^{N_{\mathrm{d}}}\left(\frac{\mu_{\exp }-\mu_{\mathrm{cal}}}{\mu_{\exp }}\right)$

AARE $\%=\frac{100}{N_{\mathrm{d}}} \sum_{i=1}^{N_{\mathrm{d}}}\left|\frac{\mu_{\exp }-\mu_{\text {cal }}}{\mu_{\exp }}\right|$

$\mathrm{SAR}=\sum_{i=1}^{N_{\mathrm{d}}}\left|\mu_{\mathrm{exp}}-\mu_{\mathrm{cal}}\right|$

$R^{2}=1-\frac{\sum_{i=1}^{N_{\mathrm{d}}}\left(\mu_{\mathrm{exp}}-\mu_{\mathrm{cal}}\right)^{2}}{\sum_{i=1}^{N_{\mathrm{d}}}\left(\mu_{\text {mean }}-\mu_{\text {cal }}\right)^{2}}$

where $N_{\mathrm{d}}$ is the number of data; $\mu_{\exp }$ is the experimental viscosity, $\mathrm{cP} ; \mu_{\text {cal }}$ is the calculated viscosity, $\mathrm{cP} ; \mu_{\text {mean }}$ is the mean value of viscosity; ARE\% is the average percentage relative error; AARE\% is the average of the absolute values of the relative error; SAR is the sum of absolute of residuals; and $R^{2}$ is the coefficient determination.

The average percentage relative error (ARE) is a measure of the bias of the model, while the arithmetic average of the absolute values of the relative errors (AARE) is an indication of the accuracy of the model. Low values of AARE show better correlation and lower errors for predicted values of viscosity using the models. The coefficient of determination $\left(R^{2}\right)$ is a measure of the precision of fit of the data. The maximum value of the $R^{2}$ is unity; and a high value indicates a high degree of agreement between the experimental and predicted viscosities.

\subsubsection{Particle size of water droplets in emulsions}

The particle size of water droplets in emulsions was analysed using an optical/video microscopy method with an LCD digital microscope (Penta View Model 44348) with the objective lens: $10 / 0.25$ and $160 / 0.17$. A drop of the sample was carefully put on the glass microscope slide (size $25.4 \mathrm{~mm} \times 76.2 \mathrm{~mm}$ and $1.0-1.2 \mathrm{~mm}$ thickness) and immediately covered with a cover glass (18 $\mathrm{mm} \times 18 \mathrm{~mm}$ and $0.13-0.17 \mathrm{~mm}$ thickness). The particle size was then determined using ImageJ TM software, following the image enhancement procedure as presented elsewhere (Alade et al. 2016b). The average diameter 

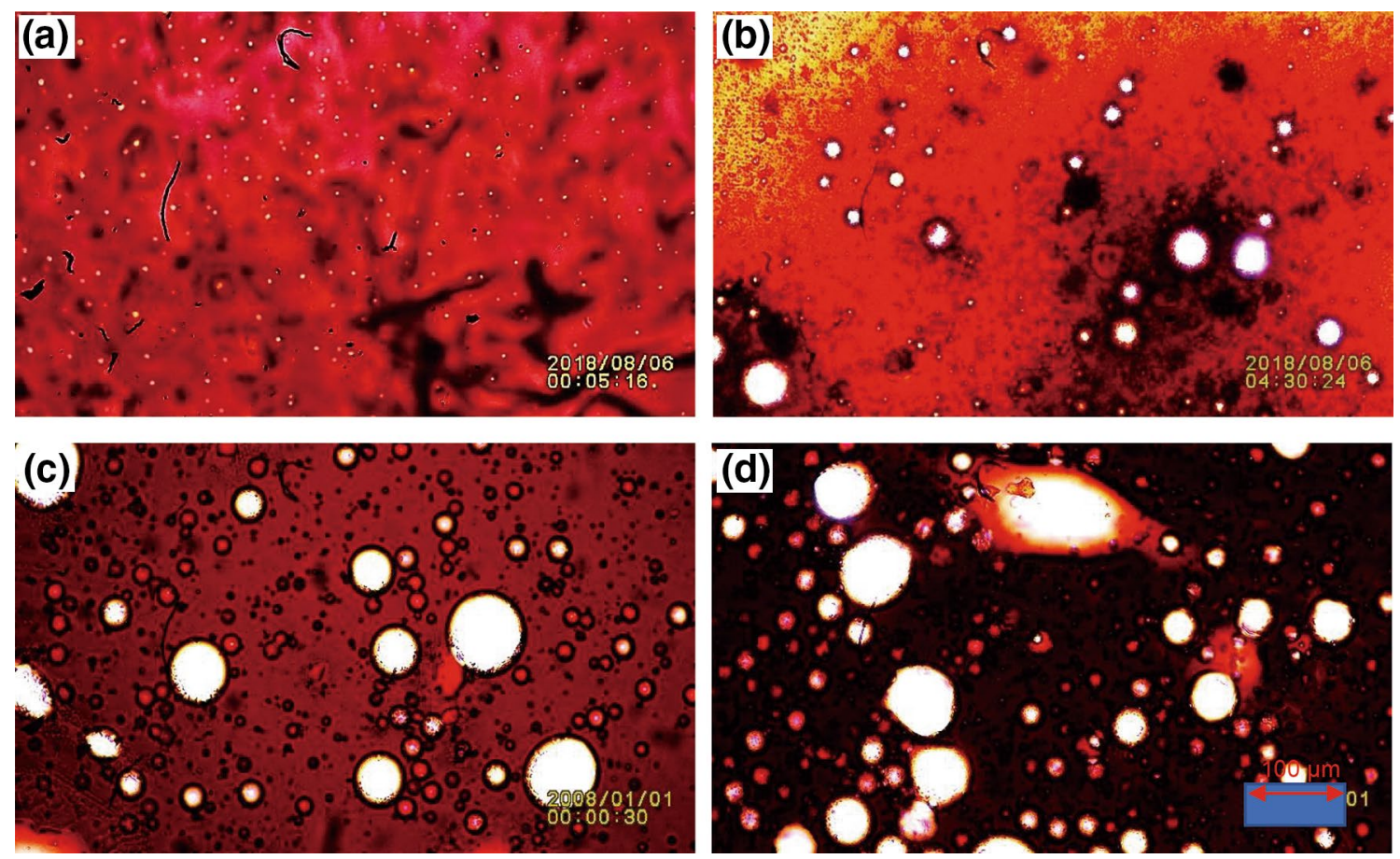

Fig. 1 Micrographic images of two-component systems. a S/O suspension, b W/O emulsion (water cut $\theta_{\mathrm{w}} \approx 10 \%$ ), c W/O (water cut $\theta_{\mathrm{w}}=20 \%-30 \%$ ) and $\mathbf{d} \mathrm{W} / \mathrm{O}$ (water cut $\theta_{\mathrm{w}}=40 \%-53 \%$ )

of particles in emulsions was estimated using volume mean diameter $\left(d_{\mathrm{v}}\right)$ as:

$d_{\mathrm{v}}=\frac{\sum_{i=1}^{n} d_{i}^{4}}{\sum_{i=1}^{n} d_{i}^{3}}$

where $d_{\mathrm{v}}$ is the size of particles in an emulsion, $\mu \mathrm{m}$, and $d_{i}$ is the diameter of the $i$ th particle, $\mu \mathrm{m}$.

The particle size distribution was expressed by the probability density distribution function (PDF)—-lognormal distribution function:

$f(x)=\frac{1}{x \sigma \sqrt{2 \pi}} \mathrm{e}^{-} \frac{(\ln (x)-\omega)^{2}}{2 \sigma^{2}}$

where $\sigma$ and $\omega$ denote the variance and mean, respectively.

\section{Results and discussion}

\subsection{Emulsion morphology}

The photomicrographic images of two-component emulsions are presented in Fig. 1. Figure 1a shows silica nanoparticles suspended in the oil phase, while Fig. 1b-d shows water droplets dispersed in the oil phase. The images show that the emulsion formed was a water-in-oil (W/O) type.

In addition, Fig. $1 \mathrm{~b}-\mathrm{d}$ shows that the size population of water droplets in the continuous oil phase increased as the water fraction increased. This is expected since the volume fraction or concentration of water in the oil phase increases. Sefton and Sinton (2010) have reported a similar observation. This observation is further corroborated in Fig. 2, which shows that the average size of the particles in the emulsion increased from $17 \mu \mathrm{m}$ to $67 \mu \mathrm{m}$ as the water fraction increased from $\approx 10 \%$ to $53 \%(\mathrm{v} / \mathrm{v})$, respectively. The sedimentation (creaming rate) of the petroleum emulsion under gravitational forces is a function of several factors including the density difference of the dispersed and aqueous phases, the droplet size and the rheology of the continuous phase. The hydrodynamic and colloidal interactions between droplets, the physical state of the dispersed or aqueous phase, the electrical charges on the droplets and the nature of the interfacial membrane (Fingas 2005) also influence this sedimentation rate. Thus, concerning the present observation, under similar conditions of formation and destabilization, it could be suggested that the emulsion with a bigger particle size would have a lower kinetic stability. 


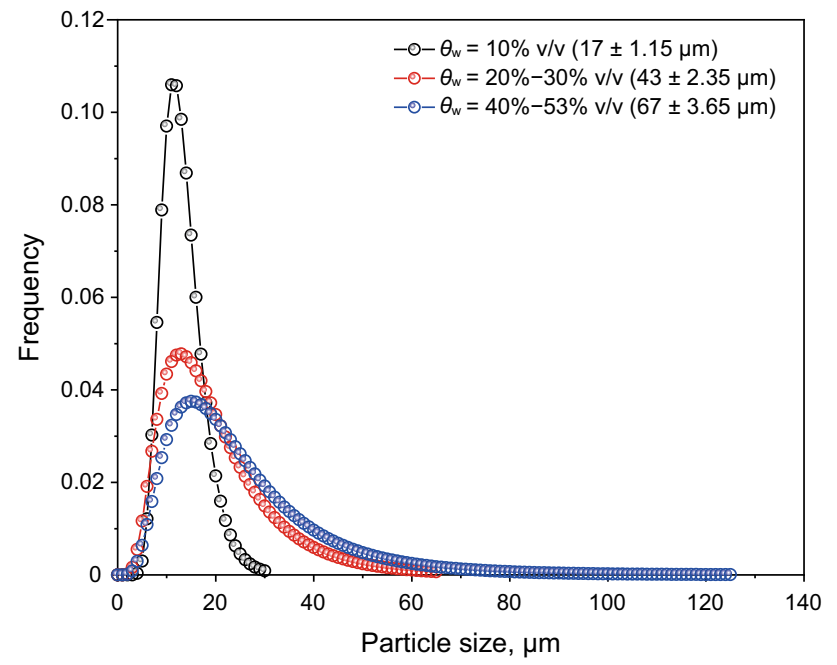

Fig. 2 Particle size distribution curves for the W/O emulsions

\subsection{Effects of weight fraction of silica particles and water cut on viscosity of the binary-component systems}

The viscosity-shear rate profile of the binary-component $\mathrm{S} / \mathrm{O}$ suspension is compared with that of original oil at different temperatures in Fig. 3. It can be observed from the figure that the original oil and the S/O suspension exhibit shear thinning (pseudo-plastic) non-Newtonian behaviour regardless of the silica content. This behaviour is, however, more observable at lower shear rates $\left(5.1-170 \mathrm{~s}^{-1}\right)$ compared to at higher shear rates $\left(200-1021.4 \mathrm{~s}^{-1}\right)$. This observation is due to higher homogenization of the particles of suspended solids at high shear rates. In addition, as expected, the viscosity of the oil reduced as the temperature increased from 30 to $70{ }^{\circ} \mathrm{C}$. Viscosity shear is known to be significant at low temperatures and shear rates (Sefton and Sinton 2010; Alade et al. 2016a, b).

Moreover, it can also be observed from the figure that the viscosity of the original heavy oil increased significantly as the silica content increased from $2 \%$ to $5.75 \%(\mathrm{wt} / \mathrm{v})$. However, at the phase fraction of $0.5 \%(\mathrm{wt} / \mathrm{v})$ there was no significant increase in the viscosity of the original oil. At $30{ }^{\circ} \mathrm{C}$ and $5.1 \mathrm{~s}^{-1}$, the viscosity of the original oil increased from 233 to $236 \mathrm{cP}$ due to the presence of $0.5 \%(\mathrm{wt} / \mathrm{v})$ silica (the relative viscosity $\eta \approx 1.01$ ); however, the viscosity of the oil containing $5.75 \%(\mathrm{wt} / \mathrm{v})$ silica was measured as 522 cP $(\eta \approx 2.25)$ under similar conditions. Generally, it was observed in this investigation that the relative viscosity decreased with increasing shear rate.

Similarly, the viscosity profile of the original heavy oil and W/O emulsions is presented in Fig. 4. As observed for the S/O system, the water cut increased the viscosity of the system. This is expected for typical water-continuous emulsions (W/O emulsions). The viscosity of the oil increased from 233 to $1353 \mathrm{cP}(\eta \approx 5.8)$ due to the presence of $53 \%(\mathrm{v} / \mathrm{v})$ water cut at $30^{\circ} \mathrm{C}$ and $5.1 \mathrm{~s}^{-1}$. The W/O emulsions were also observed to be shear thinning in nature within the operated shear rates and temperatures.

\subsection{Two-phase viscosity functions}

In order to establish a basis for the generalized viscosity function for the binary-component and ternary-component systems, the accuracy of the Arrhenius function (Eq. 10) was compared with other selected binary-component viscosity functions. Thus, the relative viscosity of S/O and W/O emulsions at low and high shear rates was fitted with the selected functions (Eqs. 6, 7 and 8) together with the Arrhenius function (Eq. 10) as presented in Figs. 5 and 6.

From Fig. 5 (S/O suspension), at a low shear rate $\left(5.1 \mathrm{~s}^{-1}\right)$, it can be observed that the fitted models including the proposed Arrhenius model provided a good fit $\left(R^{2} \approx 0.99\right)$. However, it was also observed that the level of fit is relatively weak at a higher shear rate $\left(1021.4 \mathrm{~s}^{-1}\right)$. Except for the Arrhenius function $\left(R^{2} \approx 0.93\right)$, other functions tested gave $R^{2} \approx 0.88$. This observation may be due to the fact that at high shear rates, the increased homogenization tends to make the relationship between the relative viscosity of the system and the corresponding phase fraction linear. This is also evident in the response of the viscosity of emulsion at higher shear rates.

In addition, from Fig. 6, the selected functions (Eqs. 6, 7 and 8) as well as the Arrhenius function (Eq. 10) show good fitting of the relative viscosity data of W/O emulsions. Compared to S/O systems, the functions fitted adequately both at low and high shear rates. This observation may be due to higher concentration and the particle size of water dispersed in the oil compared to the silica particles.

The function constant, $\alpha$, and the shape factor, $\beta$, are presented in Table 2 . It has been previously observed that such parameters may vary due to the type of the emulsion at hand (Pal 1998). It has also been well established that the characteristics of dispersed systems such as emulsion and suspension are influenced by the morphology (particle size and distribution) which is directly influenced by several factors including properties of the components and the formation conditions. This might have caused the observed variations in the function parameters tabulated in the tables. Moreover, there is very scarce information on the viscosity function of the heavy oil emulsions.

However, using the Pal and Rhode function (Eq. 8) to fit the binary-component viscosity of heavy oil containing different asphaltene concentrations, it was reported by Luo and $\mathrm{Gu}$ (2007) that the parameters decreased with increasing temperature. It was also observed from this 
(a)

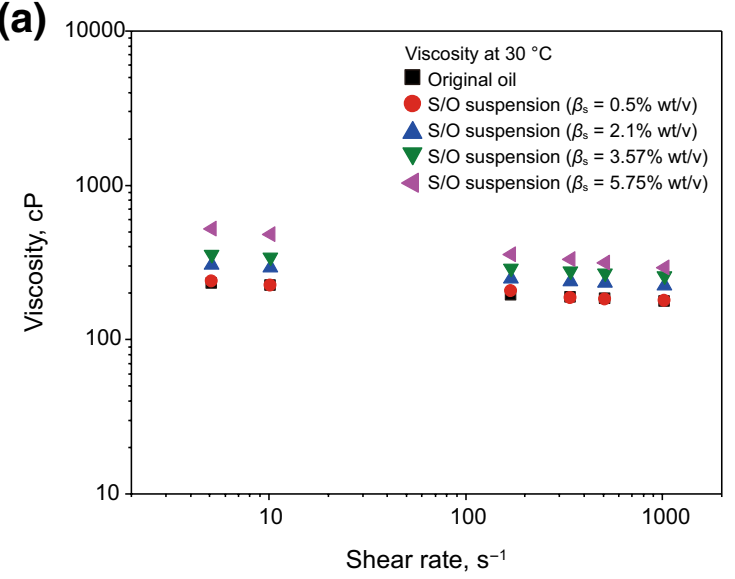

(c)

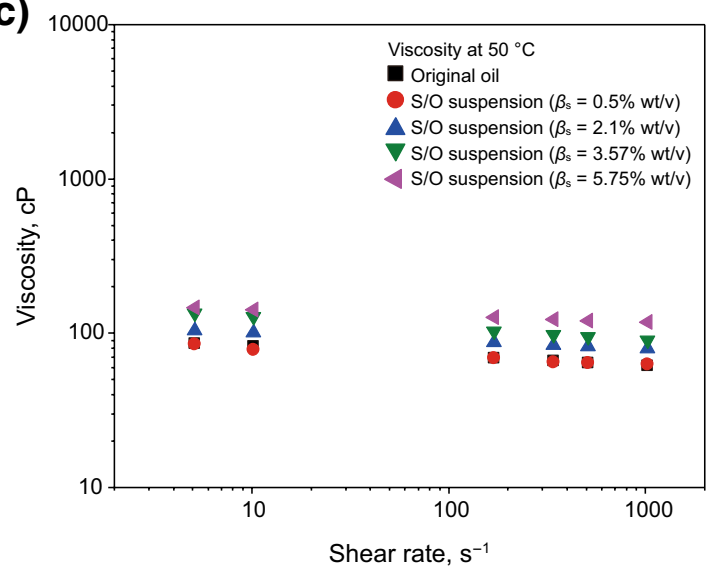

(b)

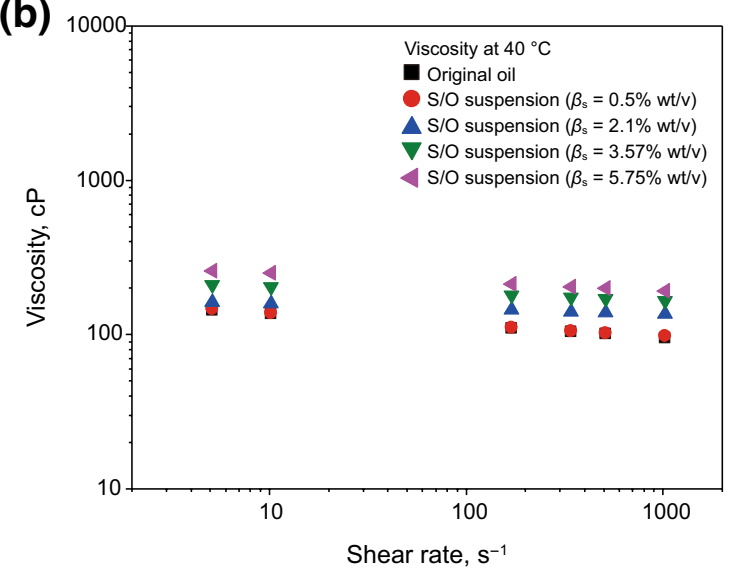

(d)

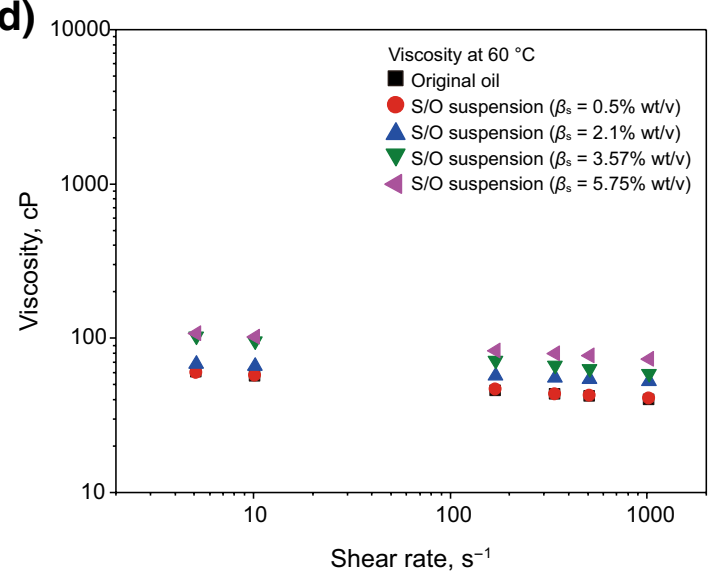

(e)

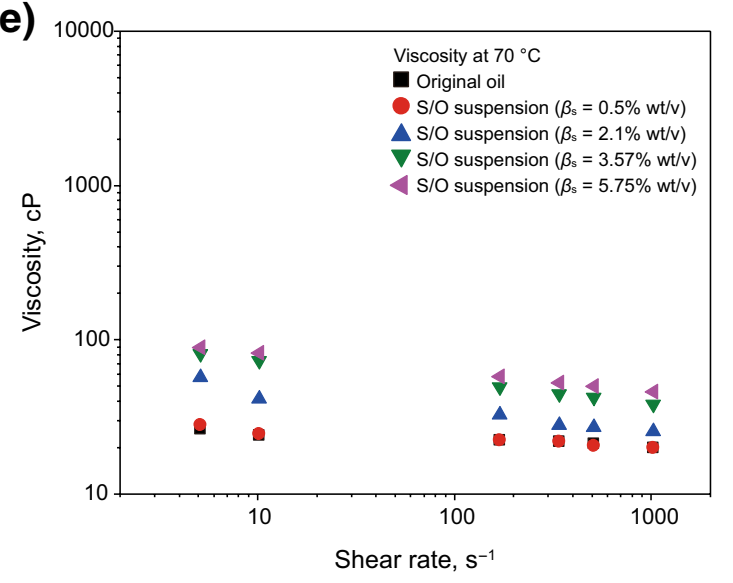

Fig. 3 The viscosity-shear rate profiles of binary-component S/O suspensions at different temperatures

investigation that the parameters mostly reduced with increasing shear rate. This observation can also be linked with the relative viscosity of the systems, which decreases as the shear rate increases.

Most notably, it is convenient to derive from the results that the Arrhenius function can be fairly compared with other functions in fitting the viscosity of the binary-component systems.

\subsection{Effect of silica content on the viscosity of the ternary-phase system}

Studies of viscosity response of petroleum fluids under different shearing conditions and temperatures find important applications in the production and flow assurance (Zhang et al. 2013; Kelesoglu et al. 2015). Figure 7 is the plots of viscosity versus shear rate of the ternary-component 

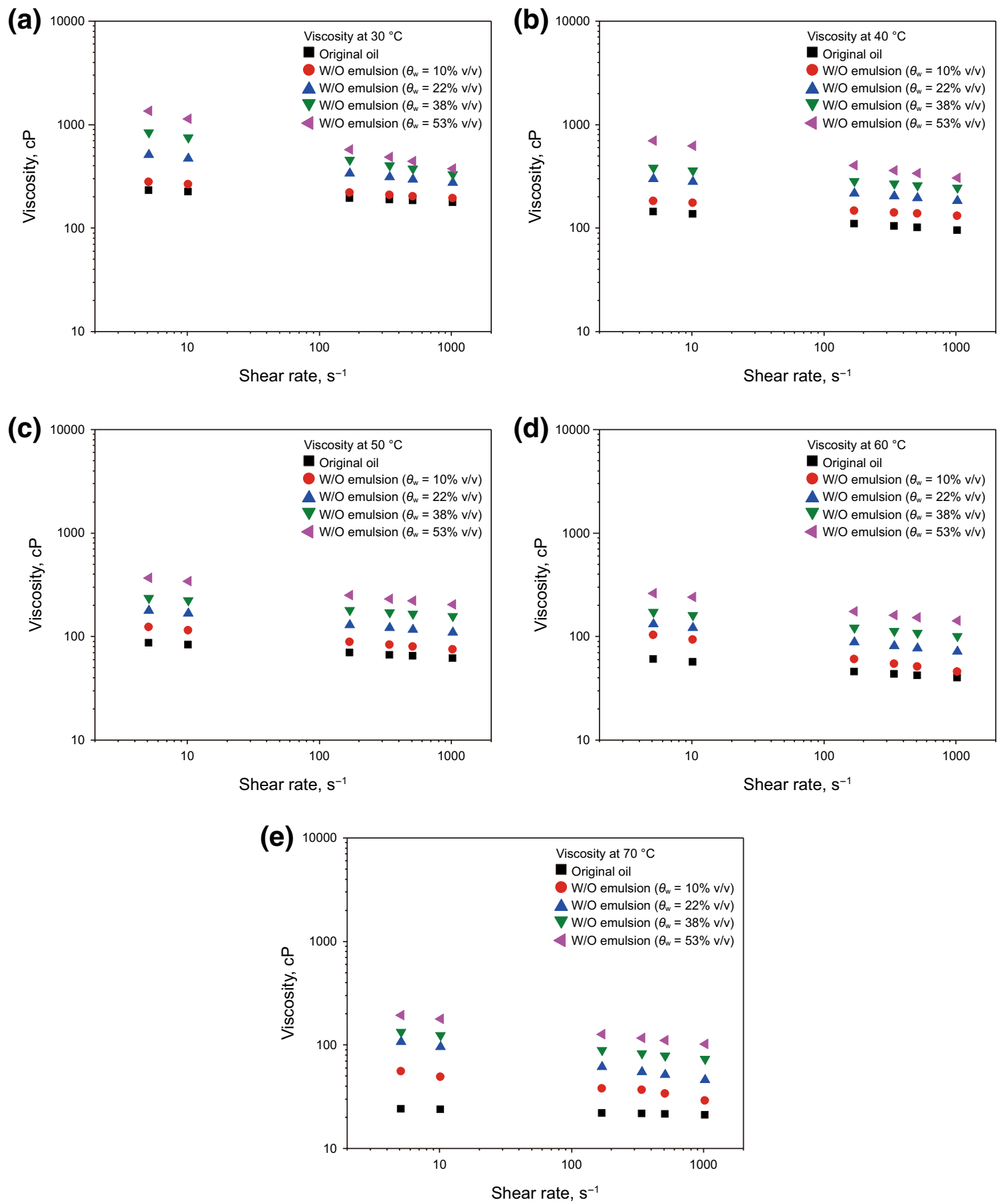

Fig. 4 The viscosity-shear rate profiles of binary-component W/O emulsions at different temperatures

systems (water cut, $\theta_{\mathrm{w}}=10 \%-53 \%(\mathrm{v} / \mathrm{v})$ and silica content, $\left.\beta_{\mathrm{s}}=0.5 \%-5.5 \%(\mathrm{wt} / \mathrm{v})\right)$ at $30{ }^{\circ} \mathrm{C}$ and shear rates of $5.1-1021.4 \mathrm{~s}^{-1}$. The viscosity-shear rate pattern observed from this figure is similar to that observed from the binarycomponent systems.

The viscosity of the ternary-component system increased as the silica content increased. In other words, the presence of silica particles increased the viscosity of the base W/O emulsion. Pal et al. (1992) reported similar observations from a clay-oil suspension with added water droplets. However, it should be noted that at low concentrations of silica $(0.5 \%-2 \%(\mathrm{wt} / \mathrm{v}))$ the increase in viscosity of the base W/O emulsion was not significant. Typically, at a water cut of 10\% (v/v) (Fig. 7a), the viscosity of the base W/O 

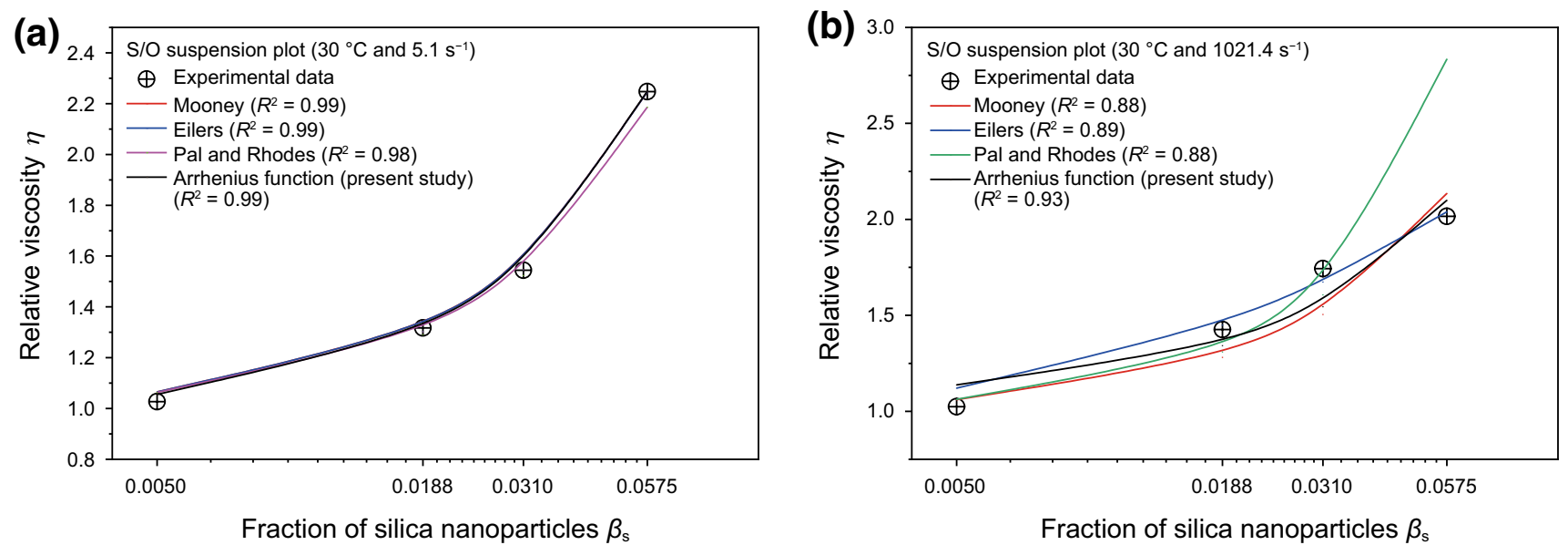

Fig. 5 Plots of relative viscosity $(\eta)$ versus fractions of silica nanoparticles using Eqs. 6, 7, 8 and 10 at low and high shear rates
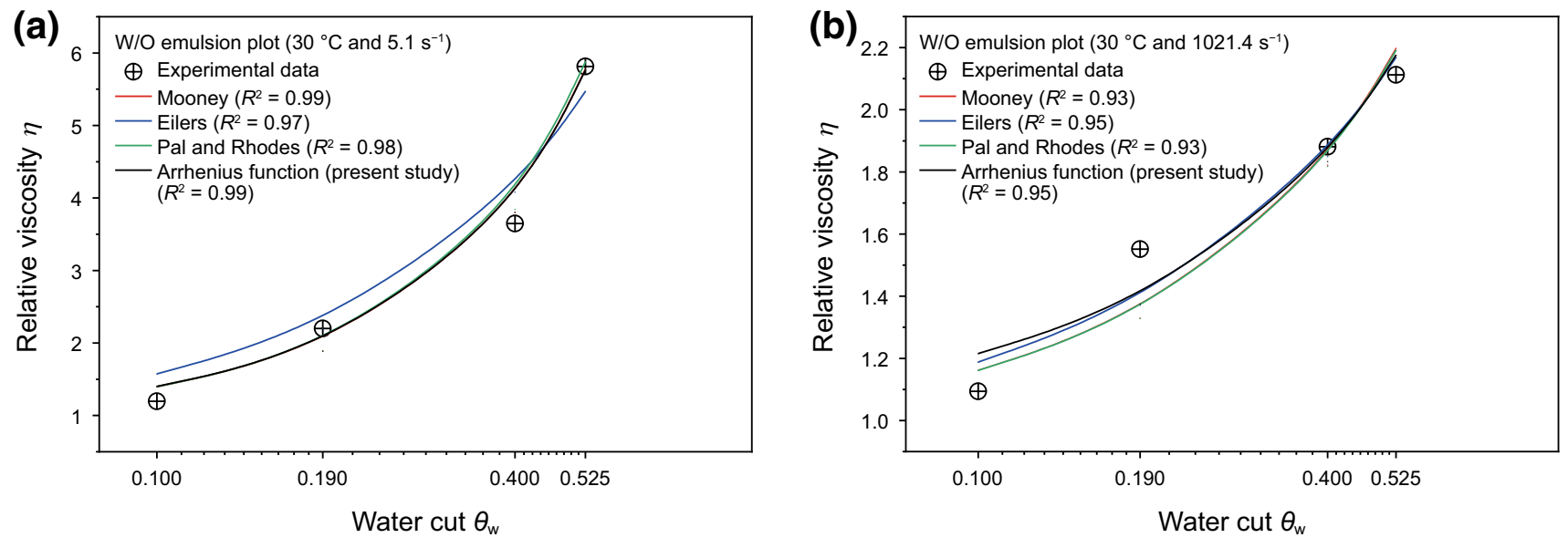

Fig. 6 Plots of relative viscosity $(\eta)$ versus water cut using Eqs. 6, 7, 8 and 10 at low and high shear rates

Table 2 Parameters for twocomponent viscosity functions

\begin{tabular}{|c|c|c|c|c|c|c|c|}
\hline \multirow[t]{2}{*}{ Function } & \multirow[t]{2}{*}{ Shear rate $\dot{\gamma}, \mathrm{s}^{-1}$} & \multicolumn{3}{|c|}{ S/O system } & \multicolumn{3}{|c|}{ W/O system } \\
\hline & & $\alpha$ & $\beta$ & $R^{2}$ & $\alpha$ & $\beta$ & $R^{2}$ \\
\hline \multirow[t]{2}{*}{ Mooney (Eq. 6) } & 5.1 & 8.67 & -5.41 & 0.99 & 2.67 & -0.67 & 0.99 \\
\hline & 1021.4 & -37.01 & -50.2 & 0.88 & -0.9 & -2.4 & 0.93 \\
\hline \multirow[t]{2}{*}{ Eilers (Eq. 7) } & 5.1 & 7.08 & 3.2 & 0.99 & 3.93 & 1.38 & 0.97 \\
\hline & 1021.4 & 13.95 & -15.19 & 0.89 & 0.26 & -0.64 & 0.95 \\
\hline \multirow[t]{2}{*}{ Pal and Rhodes (Eq. 8) } & 5.1 & 0.08 & 169.65 & 0.98 & 0.04 & 83.47 & 0.99 \\
\hline & 1021.4 & $8.53 \mathrm{E}-04$ & 15,454 & 0.88 & $9.80 \mathrm{E}-04$ & 1524.4 & 0.93 \\
\hline \multirow[t]{2}{*}{ Arrhenius (Eq. 10) } & 5.1 & 0.99 & 14.27 & 0.99 & 1.004 & 3.33 & 0.99 \\
\hline & 1021.4 & 1.08 & 11.56 & 0.93 & 1.06 & 1.37 & 0.95 \\
\hline
\end{tabular}

*The empirical parameters $\alpha$ and $\beta$ have been used in place of the constants in Eqs. 6, 7 and 8 emulsion increased from $431 \mathrm{cP}$ to $449 \mathrm{cP}(\eta \approx 1.04)$ due to the addition of $2 \%(\mathrm{wt} / \mathrm{v})$ silica particles, while the viscosity increased significantly to $553 \mathrm{cP}$ when the silica content was $5.5 \%(\mathrm{wt} / \mathrm{v})(\eta \approx 1.28)$. As expected, the viscosity of the ternary-component system also increased with increasing water cut. At low concentrations of silica particles, it can be 

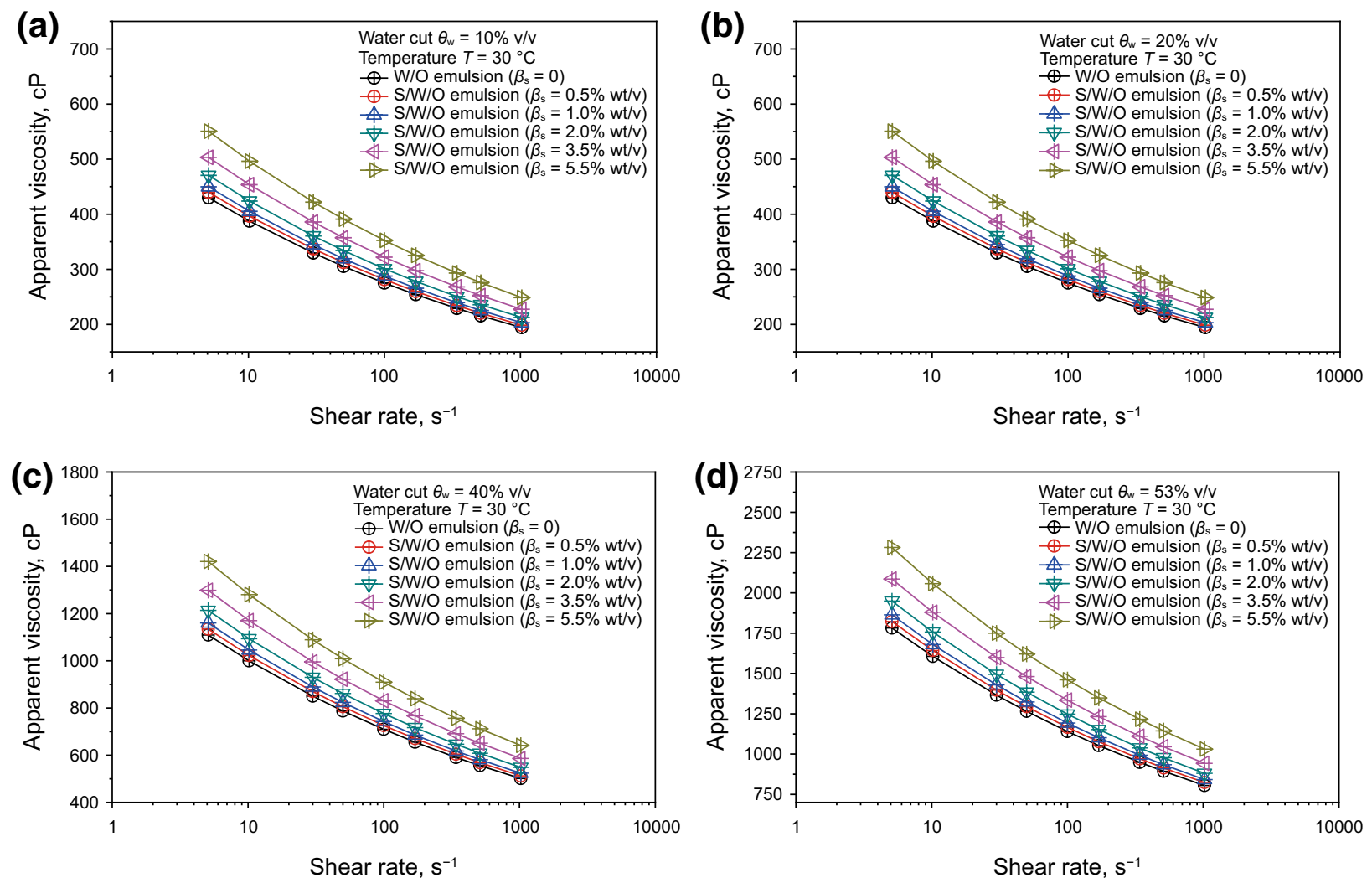

Fig. 7 Viscosity versus shear rate for the ternary-component systems at different contents of silica nanoparticles. a $10 \%$ water cut, b $20 \%$ water cut, c $40 \%$ water cut and d $53 \%$ water cut

reasoned that the solids exist in the oil phase or the homogeneous W/O phase as a very dilute suspension and thus would not impose any significant effect. On the contrary, as the concentration of the solid silica increases, the rate of agglomeration would increase, and the more packed emulsion tends to become more sensitive to the solid particles. Hence, the viscosity increases. This is similar to the phenomenon, which causes an increase in the viscosity of water internal phase emulsion (water-in-oil emulsion) of crude oil.

Moreover, from the present work, a generalized correlation to calculate the viscosity of both binary-component S/O suspensions and W/O emulsions and ternary-component $(\mathrm{S} / \mathrm{W} / \mathrm{O})$ emulsions has been proposed. The empirical parameters as well as the statistical errors are presented in Tables 3 and 4 . The analysis shows that the model accurately predicted the viscosity of the binary-component system and the ternary-component system within the limit of the conditions operated in this research. The agreement between the experimental and the predicted viscosities using the generalized correlation (Eq. 14) is presented in Fig. 8.
Table 3 Model parameters for the generalized correlation (Eq. 14)

\begin{tabular}{llll}
\hline$K_{0}$ & $\varphi$ & $\omega$ & $\phi$ \\
\hline 11.687 & 0.045 & 0.032 & 106.16 \\
\hline
\end{tabular}

Table 4 Statistical errors of Eq. 14

\begin{tabular}{llrlll}
\hline $\begin{array}{l}\text { Emulsion or sus- } \\
\text { pension system }\end{array}$ & $R^{2}$ & ARE\% & AARE $\%$ & SAR & $N_{\mathrm{d}}$ \\
\hline S/O & 0.91 & 9.93 & 21.54 & 2901 & 120 \\
W/O & 0.99 & -2.31 & 10.2 & 2423 & 120 \\
S/W/O & 0.95 & -1.04 & 5.11 & 5056 & 406 \\
\hline
\end{tabular}

\section{Conclusion}

Certain EOR methods for heavy oil, including thermal fluid flooding, may cause detachment of reservoir rock silica particles which may migrate into the produced oil or its emulsion. Several investigations have focused on the binarycomponent W/O emulsion; and rheological modelling of this type of emulsion has been presented in the literature. However, studies of the effect of solids such as silica on the 

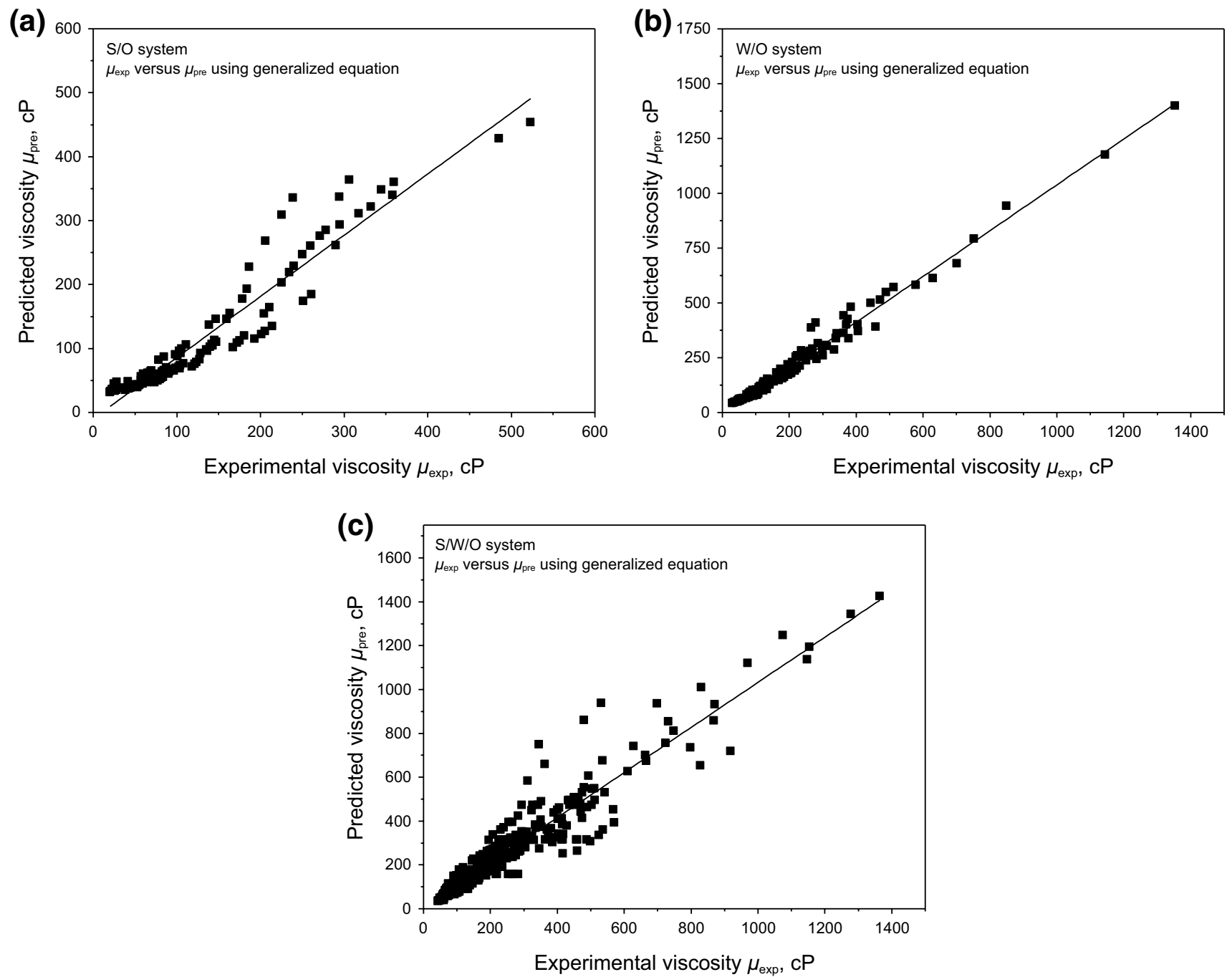

Fig. 8 Agreement between experimental and predicted viscosities using the generalized correlation (Eq. 14)

rheology of crude oil emulsion are very scarce. Therefore, the effect of silica content on the viscosity of both binarycomponent and ternary-component emulsions was studied at different shear rates and temperatures. Ultimately, a generalized correlation has been proposed to predict the viscosity of the systems. It can be concluded that the binary-component silica-oil suspension $(\mathrm{S} / \mathrm{O})$ as well as ternary-component emulsion ( $\mathrm{S} / \mathrm{W} / \mathrm{O})$ behave as shear thinning non-Newtonian fluid at the concentration of silica nanoparticles used in this research. The viscosity of the W/O emulsion was increased when the silica content was above $2 \%(\mathrm{wt} / \mathrm{v})$. However, no significant effect was noticed on the viscosity below this concentration. A generalized form of Arrhenius and power law function has been proposed in this study to predict the viscosity of both the binary- and ternary-component systems with an acceptable level of accuracy within the limit of the conditions operated in this study.
Open Access This article is distributed under the terms of the Creative Commons Attribution 4.0 International License (http://creativeco mmons.org/licenses/by/4.0/), which permits unrestricted use, distribution, and reproduction in any medium, provided you give appropriate credit to the original author(s) and the source, provide a link to the Creative Commons license, and indicate if changes were made.

\section{References}

Alade OS, Ademodi B, Sasaki K, Sugai Y, Kumasaka J, Ogunlaja AS. Development of models to predict the viscosity of a compressed Nigerian bitumen and rheological properties of its emulsions. J Pet Sci Eng. 2016a;145:711-22. https://doi.org/10.1016/j.petro 1.2016.06.040.

Alade OS, Sasaki K, Ogunlaja AS, Sugai Y, Ademodi B, Kumasaka $\mathrm{J}$, et al. Thermal tolerance and compatibility of $\mathrm{NaOH}$-poly(vinyl alcohol) in bitumen emulsification for improved flow properties. Energy Fuels. 2016b;30(11):9310-21. https://doi.org/10.1021/ ac.energyfuels.6b02060. 
Alade OS, Sasaki K, Sugai Y, Ademodi B, Nakano M. Bitumen emulsification using a hydrophilic polymeric surfactant: performance evaluation in the presence of salinity. J Pet Sci Eng. 2016c;138:66-76. https://doi.org/10.1016/j.petrol.2015.11.031.

Al-Yaari M, Al-Sarkhi A, Hussein I, Chang F, Abbad M. Flow characteristics of surfactant stabilized water-in-oil emulsions. Chem Eng Res Des. 2014;92:405-12. https://doi.org/10.1016/j.cherd .2013.09.001.

Aomari N, Gaudu R, Cabioch F, Omari A. Rheology of water in crude oil emulsions. Colloids Surf A. 1998;139(1):13-20. https ://doi.org/10.1016/S0927-7757(97)00194-5.

Balsamo V, Nguyen D, Phan J. Non-conventional techniques to characterize complex SAGD emulsions and dilution effects on emulsion stabilization. J Pet Sci Eng. 2014;122:331-45. https ://doi.org/10.1016/j.petrol.2014.07.028.

Bird RB, Stewart WE, Lightfoot EN. Transport phenomena. New York: Wiley; 2007. p. 31-4.

Clausse D, Gomez F, Dalmazzone C, Noik C. A method for the characterization of emulsions, thermogranulometry: application to water-in-crude oil emulsion. J Colloid Interface Sci. 2005;287:694-703. https://doi.org/10.1016/j.jcis.2005.02.042.

de Waele A. Viscometry and plastometry. J Oil Colour Chem Assoc. 1923;6:33-69.

Dehghan AA, Masihi M, Ayatollahi S. Phase behaviour and interfacial tension evaluation of a newly designed surfactant on heavy oil displacement efficiency; effect of salinity, wettability, and capillary pressure. Fluid Phase Equilib. 2015;396:20-7. https://doi. org/10.1016/j.fluid.2015.03.028.

Eilers V. Die Viskosität von Emulsionen Hochviskoser Stoffe als Funktion der Konzentration. Kolloid-Z. 1941;97(3):313-21. https://doi. org/10.1007/BF01503023.

Einstein A. Investigations on the theory of the Brownian movement. New York: Dover Publications, Inc; 1956.

Fakoya MF, Ahmed RM. A generalized model for apparent viscosity of oil-based muds. J Pet Sci Eng. 2018;65:777-85. https://doi. org/10.1016/j.petrol.2018.03.029.

Fingas MF, Fieldhouse B. Water-in-oil emulsions: formation and prediction. Handbook of Oil Spill Science and Technology, 2014, 225.

Fingas MF. Stability and resurfacing of dispersed oil. 2005. http:// pwsrcac.org/docs/d0026200.pdf. Retrieved December, 2018 from www.google.com.

Fortuny M, Oliveira CBZ, Melo RLFV, Nele M, Coutinho RCC, Santos AF. Effect of salinity, temperature, water content, and $\mathrm{pH}$ on the microwave demulsification of crude oil emulsions. Energy Fuels. 2007;21:1358-64. https://doi.org/10.1021/ef0603885.

Jamaluddin AKM, Bowen CT. Characteristics of heavy oil-inwater emulsions containing produced sand. Can J Chem Eng. 1994;72:380-4. https://doi.org/10.1002/cjce.5450720229.

Johnson EE, Ronningsen HP. Viscosity of 'live' water-in-crude-oil emulsions: experimental work and validation of correlations. J Pet Sci Eng. 2003;38:23-36. https://doi.org/10.1016/S0920 $-4105(03) 00020-2$.

Kelesoglu S, Barrabino PA, Humborstad SG, Simon S, Paso K, Sjoblom J. Rheological properties of highly concentrated dense packed layer emulsions (w/o) stabilized by asphaltene. J Pet Sci Eng. 2015;126:1-10. https://doi.org/10.1016/j.petrol.2014.11.031.

Kumar S, Mahto V. Emulsification of Indian heavy crude oil using a novel surfactant for pipeline transportation. Pet Sci. 2017;14:37282. https://doi.org/10.1007/s12182-017-0153-6.

Kuo C, Lee C. Treatment of oil/water emulsions using seawaterassisted microwave irradiation. Sep Purif Technol. 2010;74:28893. https://doi.org/10.1016/j.seppur.2010.06.017.

Langevin D, Poteau S, Henaut I, Argillier JF. Crude oil emulsion properties and their application to heavy oil transportation. Oil Gas
Sci Technol Rev. 2004;59(5):511-21. https://doi.org/10.2516/ ogst:2004036.

Liu Q, Yuan S, Yan H, Zhao X. Mechanism of oil detachment from a silica surface in aqueous surfactant solutions: molecular dynamics simulations. J Phys Chem B. 2012;116:2867-75. https://doi. org/10.1021/jp2118482.

Luo P, Gu Y. Effects of asphaltene content on the heavy oil viscosity at different temperatures. Fuel. 2007;86:1069-78. https://doi. org/10.1016/j.fuel.2006.10.017.

Malkin YA, Mironova MV, Ilyin SO. Flow of heavy crude oil-in-water emulsions in long capillaries simulating pipelines. J Pet Sci Eng. 2017;157:117-23. https://doi.org/10.1016/j.petrol.2017.07.024.

Mandal A, Bera A. Modeling of flow of oil-in-water emulsions through porous media. Pet Sci. 2015;12:273-81. https://doi.org/10.1007/ s12182-015-0025-x.

Maria MV, Ilyin SO. Effect of silica and clay minerals on rheology of heavy crude oil emulsions. Fuel. 2018;232:290-8. https://doi. org/10.1016/j.fuel.2018.05.164.

Martinez-Palou R, Maria de Lourdes M, Zapata-Rendon B, Mar-Juarez E, Bernal-Huicochea C, Juan de la Cruz C, et al. Transportation of heavy and extra-heavy crude oil by pipeline: a review. J Pet Sci Eng. 2011;75:274-82. https://doi.org/10.1016/j.petro 1.2010 .11 .020

Martinez-Palou R, Reyes J, Ceron-Camacho R, Ramirez-de-Santiago M, Villanueva D, Vallejo AA, et al. Study of the formation and breaking of extra-heavy-crude-oil-in-water emulsionsA proposed strategy for transporting extra heavy crude oils. Chem Eng Process. 2015;98:112-22. https://doi.org/10.1016/j. cep.2015.09.014.

Mooney M. The viscosity of a concentrated suspension of spherical particles. J Colloid Sci. 1952;6:162-70. https://doi. org/10.1016/0095-8522(51)90036-0.

Ostwald W. Über die Geschwindigkeitsfunktion der Viskosität disperser Systeme I. Colloid Polym Sci. 1925;36:99-117.

$\mathrm{Pal}$ R. A novel method to correlate emulsion viscosity data. Colloids Surf A. 1998;137:275-86. https://doi.org/10.1016/S0927 -7757(97)00374-9.

$\mathrm{Pal}$ R. Novel viscosity equations for emulsions of two immiscible liquids. J Rheol. 2001;45:509-20. https://doi.org/10.1122/1.13392 49.

Pal R. Rheology of simple and multiple emulsions. Curr Opin Colloid Interface Sci. 2011;16:41-60. https://doi.org/10.1016/j.cocis .2010.10.001.

Pal R. New models for the viscosity of nanofluids. J Nanofluids. 2014;3:260-6. https://doi.org/10.1166/jon.2014.1102.

Pal R, Rhodes E. Viscosity/concentration relationships for emulsions. J Rheol. 1989;33:1021-45. https://doi.org/10.1122/1.550044.

Pal R, Yan LY, Masliyah J. Rheology of clay-in-oil suspensions with added water droplets. Chem Eng Sci. 1992;47(5):967-70. https:// doi.org/10.1016/0009-2509(92)80223-Y.

Perazzo A, Tomaiuolo G, Preziosi V, Guido S. Emulsions in porous media: from single droplet behaviour to applications for oil recovery. Adv Colloid Interface Sci. 2018. https://doi.org/10.1016/j. cis.2018.03.002.

Roscoe R. The viscosity of suspensions of rigid spheres. Br J Appl Phys. 1952;3:267-9. https://doi.org/10.1088/0508-3443/3/8/306.

Salager J, Briceno MI, Bracho CL. Heavy hydrocarbon emulsions. Making use of the state of the art in formulation engineering. In: Sjoblom J, editor. Encyclopaedic handbook of emulsion technology. New York: Marcel Dekker; 2001. p. 455-95.

Schuch A, Deiters P, Henne J, Kohler K, Schuchman HP. Production of $\mathrm{W} / \mathrm{O} / \mathrm{W}$ (water-in-oil-in-water) multiple emulsions: droplet breakup and release of water. J Colloid Interface Sci. 2013;402:157-64. https://doi.org/10.1016/j.jcis.2013.03.066.

Schulz EN, Ambrusi RE, Miraglia DB, Schulz EP, García SG, Rodriguez JL, et al. Evaluation of oil-in-water emulsions with 
cationic-anionic surfactants mixtures for potential use in the oil industry. Colloids Surf A. 2016;490:145-54. https://doi. org/10.1016/j.colsurfa.2015.11.023.

Sefton E, Sinton D. Evaluation of selected viscosity prediction models for water in bitumen emulsions. J Pet Sci Eng. 2010;72:128-33. https://doi.org/10.1016/j.petrol.2010.03.010.

Sherman P. Rheology of emulsions. In: Sherman P, editor. Emulsion science, Chapter 4. London: Academic Press; 1968.

Sjoblom J, Aske N, Auflem IH, Brandal O, Harve ET, Saether O, Westvik A, Johnsen EE, Kallevik H. Our current understanding of water-in-crude oil emulsions: recent characterization techniques and high-pressure performance. Adv Coll Interface Sci. 2003;100-102:399-473. https://doi.org/10.1016/S0001 -8686(02)00066-0.

Soleymanzadeh A, Gahrooei HRE, Joekar-Niasar V. A new empirical model for bulk foam rheology. J Energy Res Technol. 2018;140(3):032911-1. https://doi.org/10.1115/1.4038385.

Tadros TF. Fundamental principles of emulsion rheology and their applications. Colloids Surf A. 1994;91:39-55. https://doi. org/10.1016/0927-7757(93)02709-N.

Taylor GI. The viscosity of a fluid containing small drops of another liquid. Proc R Soc Lond A. 1932;138:41-8. https://doi. org/10.1098/rspa.1932.0169.

Wen J, Zhang J, Wang Z, Zhang Y. Correlations between emulsification behaviour of crude oil-water systems and crude oil compositions.
J Pet Sci Eng. 2016;146:1-9. https://doi.org/10.1016/j.petro 1.2016.04.010

Wong SF, Lim JS, Dol SS. Crude oil emulsion: a review on formation, classification and stability of water-in-oil emulsions. J Pet Sci Eng. 2015;135:498-504. https://doi.org/10.1016/j.petrol.2015.10.006.

Xie Y, Chen Z, Sun F. Particles migrating and plugging mechanism in loosen sandstone heavy oil reservoir and the strategy of production with moderate sanding. In: Proceedings of the 5th international conference on porous media and its applications in science and engineering. ICPM5. June 22-27 (2014), Kona, Hawaii.

Yarranton H, Sztukowski D, Urrutia P. Effect of interfacial rheology on model emulsion coalescence I. Interfacial rheology. J Colloid Interface Sci. 2007;310:246-52. https://doi.org/10.1016/j. jcis.2007.01.071.

Youssif MI, El-Maghraby RM, Saleh SM, Elgibaly A. Silica nanofluid flooding for enhanced oil recovery in sandstone rocks. Egypt $\mathbf{J}$ Pet. 2018;27:105-10. https://doi.org/10.1016/j.ejpe.2017.01.006.

Zadymova NM, Skvortsovaa ZN, Traskinea VY, Kulikov-Kostyushko FA, Kulichikhin VG, Malkin AY. Rheological properties of heavy oil emulsions with different morphologies. J Pet Sci Eng. 2017;149:522-30. https://doi.org/10.1016/j.petrol.2016.10.063.

Zhang J, Yu B, Li H, Huang Q. Advances in rheology and flow assurance studies of waxy crude. Pet Sci. 2013;10:538-47. https://doi. org/10.1007/s12182-013-0305-2. 